\title{
La construcción de un ethos satírico compuesto y dinámico en la figura presidencial de Álvaro Uribe Vélez (2002-2010) en la caricatura de Matador ${ }^{\star}$
}

\author{
Diana Gómez ** \\ Ana Pedrazzini ${ }^{* * *}$ \\ Recibido: 2018-10-02. Enviado a pares: 2018-10-15. \\ Aprobado por pares: 2018-11-29. Aceptado: 2018-12-15 \\ https://doi.org/10.22395/angr.v17n34a4
}

\begin{abstract}
Resumen
Este trabajo busca caracterizar la imagen del presidente Álvaro Uribe Vélez (2002-2010) construida en las caricaturas de Matador publicadas en el diario colombiano El Tiempo durante tres períodos relevantes en sus dos gobiernos (2004, 2006 y 2010). Desde una perspectiva semiótica atenta a los signos visuales y verbales que conforman las caricaturas, analizamos el framing (encuadre) satírico a partir del cual opera la caricatura política, atendiendo a los temas tratados, a los personajes representados y a los rasgos de personalidad identificados en el personaje presidencial. La aplicación de un análisis de correspondencias -técnica de análisis multivariado-nos permitió además estudiar si existen variaciones entre los rasgos de personalidad identificados en el personaje de Uribe Vélez en cada uno de los períodos considerados. Se concluye que las caricaturas políticas se constituyeron en una lucha simbólica por la representación del mandatario, dado que Matador se focalizó en los aspectos negativos de su accionar, asoció algunas de sus decisiones juzgadas como positivas por la opinión pública con hechos y rasgos negativos y cuestionó el ethos construido por Álvaro Uribe Vélez en su discurso. Se encontró que las carencias en las cinco dimensiones de rasgos de personalidad identificados en el personaje de Matador (competencia, integridad, estabilidad emocional y capacidad de decisión, lealtad y responsabilidad, carisma y empatía) variaron en algunas coyunturas particulares durante los dos mandatos, dependiendo de la agenda política. Se interpretan así los rasgos identificados en el personaje como un ethos satírico compuesto y dinámico.

Palabras clave: rasgos de personalidad; ethos satírico; Colombia; caricatura política; presidente Álvaro Uribe Vélez; encuadre mediático; imaginarios sociales; análisis multivariado.
\end{abstract}

Este artículo es el resultado de la tesis de maestría en Análisis del Discurso de la Facultad de Filosofía y Letras de la Universidad de Buenos Aires, llevada a cabo por Diana Gómez, bajo la dirección de la doctora Ana Pedrazzini. La tesis lleva como título El presidente Álvaro Uribe Vélez (2002-2010) en la caricatura política de Matador en El Tiempo. El artículo ha sido parcialmente financiado por PIP Conicet 0142, Universidad Nacional del Comahue C130, Agencia Nacional de Promoción Científica y Técnica PICT 2014-2929.

" Estudiante de maestría en Análisis del Discurso de la Universidad de Buenos Aires, licenciada en Historia de la Universidad Nacional de Colombia, sede Bogotá, docente de la Universidad Nacional de José C. Paz, integrante de Gecumesal (Grupo de Estudios sobre Cultura, Medios y Sociedad en América Latina) adscrito a la Facultad de Ciencias Sociales, en la Universidad de Buenos Aires.dgomez@unpaz.edu.ar. Orcid: https://orcid.org/0000-0001-5765-0512

... Doctora en Ciencias de la Información y de la Comunicación por el Celsa, Universidad París-Sorbonne y doctora en Ciencias Sociales por la Universidad de Buenos Aires, investigadora Asistente de Conicet, integrante del Grupo Vinculado de Estudios Culturales y Cognitivos, IPEHCS-Conicet, Universidad Nacional de Comahue. ana.pedrazzini@crub.uncoma.edu.ar. Orcid: https://orcid.org/0000-0003-0524-0305 


\title{
The construction of a composite and dynamic satirical ethos in the presidency of Álvaro Uribe Vélez (2002-2010), in Matador's Cartoons
}

\begin{abstract}
This work seeks to characterize the image of former Colombian President Álvaro Uribe Vélez (20022010) as crafted in Matador's cartoons published in the Colombian newspaper El Tiempo during three relevant periods in his two governments $(2004,2006$, and 2010). From a semiotic perspective, mindful of visual and verbal signs that make cartoons, we analyze the satirical framing from which the political cartoon operates based on the topics addressed, the characters that are represented, and personality that can be identified in the presidential character. A correspondence analysis - a multivariate analysis technique - also allowed us to study whether there are variations between the personality traits identified in Uribe Vélez' character in each of the aforementioned periods. It is concluded that the political cartoons constituted a symbolic struggle for the depiction of the president, given that Matador focused on the negative aspects of his actions, as well as associated some of his decisions judged as positive by the public with negative facts and features, and questioned the ethos built by Álvaro Uribe Vélez in his speech. It was found that the shortcomings in the five dimensions of personality traits identified in the depiction made by Matador (competence, integrity, emotional stability and decision-making, loyalty and responsibility, charisma and empathy) varied in some situations during the two terms, depending on the political agenda. Thus, the features identified in the character are interpreted as a composite and dynamic satirical ethos.
\end{abstract}

Keywords: personality traits; satirical ethos; Colombia; political cartoon; president Álvaro Uribe Vélez; media framing; popular consciousness; multivariate analysis.

\section{A construção de um ethos satírico composto e dinâmico na figura presidencial de Álvaro Uribe Vélez (2002-2010) na caricatura de Matador}

\begin{abstract}
Resumo
Este artigo busca caracterizar a imagem do presidente Álvaro Uribe Vélez (2002-2010) construída nos trabalhos do caricaturista Matador publicadas no jornal colombiano El Tiempo durante três períodos relevantes em seus dois governos (2004, 2006 e 2010). A partir de uma perspectiva semiótica atenta aos sinais visuais e verbais que formam as caricaturas, analisamos o framing (enquadramento) satírico a partir do qual a caricatura política opera, que atende aos temas tratados, aos personagens representados e aos traços de personalidade identificados no personagem presidencial. A aplicação de uma análise de correspondências — técnica de análise multivariada — nos permitiu ainda estudar se existem variações entre os traços de personalidade identificados no personagem de Uribe Vélez em cada um dos períodos considerados. Conclui-se que as caricaturas políticas se constituíram em uma luta simbólica pela representação do mandatário, dado que o Matador se enfocou nos aspectos negativos de seu agir, associou algumas de suas decisões julgadas como positivas pela opinião pública com feitos e traços negativos e questionou o ethos construído por Álvaro Uribe Vélez em seu discurso. Descobriu-se que as carências nas cinco dimensões de traços de personalidade identificados no personagem de Matador (competição, integridade, estabilidade emocional e capacidade de decisão, lealdade e responsabilidade, carisma e empatia) variaram em algumas conjunturas particulares durante os dois mandatos, a depender da agenda política. Os traços identificados no personagem são assim interpretados como um ethos satírico composto e dinâmico.

Palavras-chave: traços de personalidade; ethos satírico; Colômbia; caricatura política; presidente Álvaro Uribe Vélez; enquadramento midiático; imaginários sociais; análise multivariada.
\end{abstract}




\section{Introducción}

La creciente personalización, personificación y espectacularización de la política (Tillier, 1997; McAllister, 2007; Rico, 2009; Garzia, 2011) se encuentra íntimamente ligada al accionar de los medios de comunicación. Estos seleccionan algunos aspectos de la realidad percibida y los resaltan por sobre otros, lo que se conoce como framing (Entman, 1993). Destacan así de manera constante información sobre los atributos personales y profesionales de las figuras públicas. Este protagonismo de los dirigentes políticos los torna susceptibles de convertirse en el centro de críticas como resultado de sus inoperancias o desaciertos en las decisiones que toman. Una de las formas discursivas por excelencia que focaliza en los hechos y rasgos negativos del accionar de estas figuras públicas es la caricatura política, y es el jefe de Estado, en regímenes presidenciales, un blanco privilegiado (Pedrazzini, 2011). El autor de caricaturas políticas opera exagerando y distorsionando aspectos de la realidad con el fin de develar lo que percibe como la naturaleza intrínseca de aquello que retrata (Abraham, 2009). En este ejercicio de framing satírico, el dibujante destaca lo malo y vergonzoso (El Refaie, 2009) y procede mediante atribución de culpa y responsabilidad (Greenberg, 2002). Es a partir de este enfoque que la caricatura política se constituye como una imagen satírica y, por lo tanto, crítica, irreverente y burlesca (Montealegre, 2014). Asimismo, en la explicación que busca dar de los acontecimientos que aborda simplifica la complejidad usualmente inherente a todo fenómeno social (Van Hecke, 2016).

La caricatura política interviene en el escenario social como una declaración firmada que busca moldear opiniones y generar reflexión dentro de la comunidad en la que es publicada (Shelton Caswell, 2004; Gantús, 2007; Sánchez Guevara, 2011). Al mismo tiempo, debido a su fuerte componente satírico, es considerada un arma eficaz para "desacralizar" todo aquello que es considerado digno de relevancia (Montealegre, 2014).

Junto con De Sousa y Medhurst (1980), podríamos decir que las caricaturas políticas son artefactos que crean, mantienen e identifican a la cultura. En este sentido, participan en la construcción social de imaginarios de una época (Gantús, 2007; Carmona, 2009; Montealegre, 2014), erigiéndose como un lugar de memoria que permite visualizar subjetividades que prevalecen en distintas situaciones compartidas socialmente (Levín, 2013; Burkart, 2017).

Fiel a su espíritu satírico, el autor de caricaturas políticas busca develar lo que considera injusto socialmente o digno de ser cuestionado frente al obrar de la clase dirigente. Uno de los aspectos sobre los que construye su crítica son los rasgos físicos y de personalidad de las mujeres y los hombres políticos. Como señalan De Sousa y Medhurst (1980), estos rasgos estereotipados se convierten en formas convencionales de representar a ciertos personajes de la escena pública. Sin embargo, como plantean los autores, la selección de los rasgos físicos o psicológicos que el caricaturista utiliza sobre su blanco de crítica no siempre son fabricados por él, sino que suelen existir en la memoria popular o en la tradición gráfica antes de ser ampliados y caricaturizados por el dibujante. 
Esto sostienen también algunos profesionales, como Julio César González, Matador' cuyas caricaturas políticas aparecen diariamente en el matutino colombiano El Tiempo-el de mayor tirada del país- desde 2003. Según él, el caricaturista no crea la caricatura, son los personajes mismos los que hacen su caricatura (Solano, 2016). Su mirada perspicaz y osada (Colarte, 2006) le valieron convertirse en el dibujante más asiduo del diario y a juzgar por las recientes amenazas de muerte que recibió por sus caricaturas del expresidente Álvaro Uribe Vélez (Semana, 2018; Zamora, 2018), su trabajo tiene un notable impacto social.

Matador admite que caricaturizar al entonces presidente Álvaro Uribe al inicio de su mandato les costó a los dibujantes porque no veían en él un rasgo sobresaliente, pero a medida que lo fueron conociendo, la tarea se les simplificó (Artunduaga, 2014). Tanto es así que el exmandatario se ha convertido en el personaje que más se le facilita dibujar (Quiroz, 2013). En una nota publicada en la revista Semana el 23 de agosto de 2014, Matador sostiene que "entender la política no es tan difícil, porque se trata de entender las pasiones del ser humano. Eso es exactamente lo que pasa con Álvaro Uribe y su lucha por el poder". Asegura que encontrarles a los personajes su lado débil no es difícil:

Solo basta con bajarlos del pedestal. El problema es que la prensa deforma mucho la realidad y engrandece a sus protagonistas, cuando Uribe, en verdad, es un loquito bajito en Crocs. Que tenga poder, a mí me tiene sin cuidado. Para eso está el humor, para transgredir el culto a la personalidad y burlarse de esos tipos allá arriba (Semana, 2014).

Teniendo en cuenta lo indicado anteriormente, el estudio de las caricaturas del presidente Uribe Vélez que circularon a través de la prensa -y en particular las elaboradas por Matador en El Tiempo- se hace especialmente interesante. Aún más si consideramos los altos índices de popularidad que el jefe de Estado mantuvo durante sus gobiernos. Al finalizar su segundo mandato, su nivel de aceptación era de 80 \% y hoy en día alcanza el 58 \% (González, 2010; El País, 2010; El Espectador, 2017).

Así, en el presente trabajo caracterizaremos la representación que Matador construyó del presidente Álvaro Uribe Vélez durante su gestión a partir del análisis de las temáticas abordadas, los personajes representados y los rasgos de personalidad atribuidos al mandatario. Estudiaremos también las posibles variaciones de esta representación en los períodos analizados. Movilizando además los conceptos de ethos prediscursivo (Amossy, 2000; Charaudeau, 2005) y ethos posdiscursivo satírico (Pedrazzini, 2017), estudiaremos el ethos construido en torno al personaje. Para ello, analizaremos un corpus de caricaturas publicadas en El Tiempo durante tres períodos de relevancia política en el país (2004, 2006 y 2010). La articulación de un análisis de grano fino con técnicas estadísticas nos permitirá adoptar una lente atenta tanto a las regularidades como a las especificidades del corpus.

Matador es un caricaturista colombiano, nacido y residente en Pereira, que publica su trabajo en diversos medios gráficos del país. Es el caricaturista más asiduo del diario El Tiempo. En 2004 publica el libro Humor Matador y en 2011 Políticos al desnudo. Por su trayectoria recibió el Premio Nacional de Periodismo Simón Bolívar en 2009 y el Premio a mejor caricatura en 2013, otorgado por el Círculo de Periodistas de Bogotá. 
El artículo está estructurado de la siguiente manera. El próximo apartado está destinado a justificar la importancia que los rasgos de personalidad tienen en la construcción de la imagen mediática de un dirigente político, así como también propone unas dimensiones para operativizar su análisis. Seguidamente, se realiza una revisión de antecedentes teóricos y empíricos sobre la noción de ethos pre y posdiscursivo que juzgamos de mucha utilidad para, a continuación, revisar algunos trabajos que se han interesado por el presidente Uribe Vélez. Luego nos adentramos en nuestro estudio, presentando los objetivos, las hipótesis, el corpus y las técnicas de análisis. Desglosaremos nuestros resultados y presentaremos algunas caricaturas como ejemplos. El apartado final discutirá los resultados a la luz de trabajos previos y los pondrá en relación con las hipótesis planteadas.

\section{Los rasgos de personalidad de un dirigente político}

Se ha demostrado que la opinión formada por los votantes sobre la personalidad de los políticos influye considerablemente en su voto electoral y puede ser equivalente o superior a la filiación política (Kinder, Mark, Abelson y Fiske, 1980; Glass, 1985; Miller, Wattenberg y Malanchuk, 1986; Miller y Krosnick, 2000). Una línea de investigación se centra en la evaluación que los lectores hacen de los atributos de la personalidad de los candidatos. Miller et al. (1986), Kinder et al. $(1980,1986)$ y Wattenberg $(2004$; 2006) identifican rasgos positivos y negativos que los votantes atribuyen a sus líderes políticos así como los rasgos de personalidad con los que los ciudadanos describen a un presidente ejemplar en dimensiones como la competencia, la integridad, la confiabilidad, el liderazgo y el carisma.

A partir de algunos de estos estudios, y en el marco de una investigación sobre la construcción de la imagen de los dirigentes políticos en la prensa satírica, Pedrazzini (2017) propone cuatro dimensiones de rasgos de personalidad que pueden ser atribuidos a los hombres y mujeres públicos: competencia, fiabilidad, integridad y carisma y empatía. Cada una de estas dimensiones se compone de diversas categorías que tienen rasgos positivos y negativos. Competencia incluye formación, inteligencia lógica y eficiencia. Integridad incluye humildad, moralidad y sinceridad. Fiabilidad está conformada por la estabilidad emocional, la racionalidad, la capacidad de tomar decisiones y la lealtad. Finalmente, la dimensión carisma y empatía incluye habilidades de comunicación y escucha, autoridad y popularidad.

Estas dimensiones se encuentran asociadas a la imagen de sí que construyen los dirigentes políticos y a los rasgos que ellos mismos desean resaltar ante sus audiencias. La noción de ethos resulta así central en el estudio de la imagen de los dirigentes políticos.

\section{Ethos pre y posdiscursivo}

El ethos, desde la retórica aristotélica, es una de las pruebas que el orador construye para dar buena impresión de sí, convencer al auditorio y ganar su confianza. Roland Barthes lo definió como los rasgos de carácter que el orador debe mostrar al auditorio para dar 
una buena impresión (1982, p. 63). Sin embargo, el ethos no es solo discursivo a este se antepone un ethos prediscursivo (Amossy, 2000; Charaudeau, 2005).

En la imagen que el locutor proyecta de sí mismo, hace uso de datos sociales e individuales previos que necesariamente juegan un rol en la interacción y contribuyen a darle fuerza a su palabra. En esa elaboración de su imagen, el locutor se apoya en elementos preexistentes a partir de la idea que el público se forma de este antes de que tome la palabra, o a través de la posición que le confiere su estatus (Amossy, 2000). De tal manera, el ethos prediscursivo se elabora sobre la base del rol que cumple el orador en el espacio social y se relaciona con sus funciones institucionales, su jerarquía y su poder. No obstante, también se construye sobre la base de la representación colectiva del estereotipo que circula sobre su persona (Amossy, 2000). En este mismo sentido, Charaudeau (2005) concibe el ethos como una doble articulación:

El ethos es una cuestión de cruce de miradas: mirada del otro sobre el que habla, mirada de quien habla sobre la forma en que cree que el otro lo ve. Ahora bien, este otro, para construir la imagen del sujeto que habla, se apoya tanto en los datos preexistentes al discurso, lo que sabe a priori del hablante, como en los proporcionados por el acto mismo de habla (p. 88. Traducción de las autoras).

Teniendo en cuenta estas nociones de ethos prediscursivo y discursivo, Pedrazzini (2017) construye la noción de ethos posdiscursivo satírico, el cual está construido sobre la base del discurso, las acciones y las actitudes de un individuo en relación con la reputación y el estatus institucional y social que se le atribuyen. En el ethos posdiscursivo "se hace eco del ethos pre-discursivo y el ethos discursivo para constituir una nueva imagen del individuo, mediática y, por lo tanto, diferida, configurada por los autores de los medios" (Pedrazzini, 2017, p. 381). El ethos posdiscursivo está asociado a los procesos de deconstrucción y construcción que los medios llevan a cabo sobre los hechos noticiosos. En el caso de la prensa satírica, recordemos que el framing amplifica algunos aspectos de la realidad para centrarse en lo negativo (El Refaie, 2009; Pedrazzini, 2013). El ethos puede construirse sobre la base de algún rasgo de personalidad predominante o bien estar integrado por varios rasgos. En este último caso, se habla de ethos compuesto (Constantin de Chanay, 2005) o híbrido (Amossy, 2010).

\section{Rasgos de personalidad y ethos prediscursivo de Uribe Vélez}

Revisaremos a continuación algunos estudios que han focalizado en el presidente Uribe Vélez. Existen trabajos exploratorios que refieren a algunos rasgos de personalidad atribuidos al mandatario en corpus acotados de caricaturas. Vargas (2013) identifica en las caricaturas elaboradas por el dibujante Vladdo para la revista Semana, que durante su primer gobierno (2002-2006), el artista critica la imagen mesiánica del Presidente y su autoritarismo. Mondragón y Paz (2013) comparan los rasgos de personalidad más característicos de los presidentes Álvaro Uribe y Juan Manuel Santos a partir de un análisis semiótico en profundidad de cuatro caricaturas de Matador publicadas en El Tiempo durante 2010 y 2011. Concluyen que, durante 2010, Álvaro Uribe es representado por el caricaturista como 
una persona obsesiva, autoritaria, soberbia, poderosa, inalcanzable, inteligente, cínica e hipócrita. Pero una vez que Santos asumió la presidencia en agosto de 2010, la imagen de Uribe Vélez es modificada por Matador al ser representado como una persona frágil, ansiosa, impotente y preocupada por las acciones de su sucesor.

Desde otro marco, un análisis de interés es el que realiza Arrieta (2014) sobre las construcciones ethoticas en el discurso del presidente Álvaro Uribe Vélez durante sus ocho años de gobierno. La autora sostiene que en este discurso presidencial imperó la construcción del miedo a través de la imposición de una lógica amigo/enemigo en la que solo tenía cabida la guerra como un "acontecimiento inevitable" para superar el conflicto y lograr la paz en Colombia. La construcción del miedo operó, para ella, como un mecanismo que le permitió al Presidente instaurar en su discurso la figura de un mal, una amenaza o posible amenaza que debía ser enfrentada convirtiéndose en referente compartido en la comunidad.

A partir de lo anterior, Arrieta identifica cinco ethe en el discurso del Presidente: un ethos autoritario, un ethos de responsabilidad, un ethos religioso, un ethos paternalista y un ethos mesiánico. Plantea que el ethos autoritario y el ethos de responsabilidad fueron construidos a partir del personalismo y del uso del pronombre en primera persona. De esta manera, era él quien culpaba, amenazaba y ordenaba a sus enemigos. Estas características del discurso del Presidente fueron asociadas, por un lado, a la manifestación de un carácter "decidido", "fuerte", "valeroso" y "necesario" para el bien común en Colombia y, por el otro, lo impregnaron de una aureola de honestidad en su accionar y, por tanto, en una autoridad que responde por sus actos.

Arrieta identifica un ethos religioso en el discurso del presidente Álvaro Uribe como soporte de la fundación de una moral para la construcción del miedo (relación amigo/enemigo). Este ethos religioso, a su vez, da lugar a otras dos configuraciones ethoticas: paternalismo y mesianismo. Según la autora, estas tres instancias se configuraron estratégicamente y le permitieron al mandatario presentarse ante la comunidad como un gobernante virtuoso, que tenía el poder de erradicar el "mal" que había tenido a Colombia sumida en la miseria (2014, p. 28). El Presidente hace uso de la metáfora del padre generoso y protector que cuida a sus hijos para construir un ethos paternalista-protector:

El padre de familia cuando se va a morir hace el inventario de su vida, lo llama a examen y si dejó a los hijos educados con buen ejemplo y con una dotacioncita en lo básico, se muere tranquilo. En Colombia, mientras no haya paz, el padre de familia, por buen padre de familia que haya sido no se puede morir tranquilo².

Según Arrieta, en este discurso se instaura, además, la imagen de un ser superior, un pastor que cuida de su rebaño y que posee la sabiduría para guiarlo por el buen camino. Recurriendo a la figura bíblica del buen padre, "el mandatario hace de su mensaje un consejo útil, una verdad con cierta fuerza moral, absoluta e irrefutable" (2014, p. 29). De acuerdo con los resultados del estudio de Arrieta podemos decir que el ethos discursivo

2 Álvaro Uribe Vélez, 22 de enero de 2004, ante el cuerpo diplomático acreditado en Bogotá. 
del presidente Álvaro Uribe fue dinámico y compuesto durante sus ocho años de gobierno, puesto que se movió entre el autoritarismo, el paternalismo y el mesianismo. También se asoció con la imagen de un mandatario decidido, responsable y honesto.

\section{Presentación del estudio}

Teniendo en cuenta los antecedentes presentados en los apartados anteriores, este trabajo tiene los siguientes objetivos:

- Identificar las temáticas abordadas por Matador en sus caricaturas y analizar su variación según los períodos considerados.

- Caracterizar la representación que Matador realiza del presidente Álvaro Uribe considerando, por un lado, los rasgos de personalidad que se le atribuyen y por otro, junto a qué personajes es dibujado.

- Analizar la existencia de variaciones temporales en la representación que Matador realiza del presidente Álvaro Uribe.

- Interpretar los rasgos de personalidad identificados en el personaje Álvaro Uribe en tanto ethos posdiscursivo satírico y relacionarlos con el ethos discursivo compuesto del presidente detectado en estudios previos.

En tanto imagen satírica, prevemos que la caricatura que Matador crea en torno al presidente Álvaro Uribe Vélez se basa principalmente en rasgos de personalidad negativos. Probablemente, estos se acentúen en distintos momentos de sus dos gobiernos, lo que da lugar a una imagen dinámica y permeable a las vicisitudes del escenario político. Si se consideran los estudios previos mencionados más arriba, anticipamos que algunos de estos rasgos sean los de "obstinado", "autoritario" y "soberbio", dando lugar así a un ethos compuesto.

En relación con ciertos rasgos positivos, tales como responsable, decidido, mesiánico, paternalista, capaz de sacrificarse por el bien de Colombia, identificados en el discurso oral del mandatario, proponemos una estrategia retórica planteada en trabajos anteriores (Pedrazzini, 2017) sobre cómo opera la sátira y, específicamente, la caricatura política. Esta consiste en polarizar hacia lo negativo cuando aborda alguna acción o rasgo del dirigente que goza de aceptación pública, asociando lo positivo a otro rasgo que se critica, o bien directamente no dar cuenta de esas acciones o rasgos.

Sobre la base de las formulaciones realizadas, sostenemos que las caricaturas elaboradas por Matador en el diario El Tiempo sobre el presidente Álvaro Uribe Vélez en cada uno de los períodos analizados, pueden ser leídas como espacios de disputa social por la representación de la figura del Presidente, puesto que se enfrentaron a la imagen pública construida por el mandatario y a los altos índices de popularidad que mantuvo durante sus dos gobiernos, incluso al término del segundo. 


\section{Aspectos metodológicos}

Con el fin de estudiar la construcción de la representación que Matador hace del presidente Álvaro Uribe Vélez y si esta varió durante sus dos mandatos, elegimos tres períodos de relevancia en el contexto político en Colombia. Estos períodos podrían ser considerados como "lugares políticos comunes" (De Sousa y Medhurst, 1982) en tanto son temas predecibles y perdurables de la agenda política: las elecciones presidenciales constituyen un factor común a los tres períodos y además se suma a ellas el fin de mandato en el tercer período.

El primer período corresponde al segundo año de gobierno del presidente, 2004, durante el cual se aprueba en el Congreso la reelección inmediata de la presidencia y se establece el diálogo con las organizaciones armadas de extrema derecha en el país. El segundo período corresponde al año 2006, fecha en que se realizan las elecciones presidenciales (28 de mayo), las cuales tuvieron la particularidad de contar por primera vez en la historia de Colombia con un candidato presidencial que ejercía el poder y que además fue reelecto. Finalmente, el tercer período lo constituyen los últimos tres meses del gobierno del Presidente, que culmina el 7 de agosto de 2010. Su importancia radica en el balance que se hace de la gestión del gobierno de Álvaro Uribe Vélez para la sociedad colombiana tras ocho años de gobierno y su intención de persistir en el poder a través de su exministro, Juan Manuel Santos.

A partir de este recorte temporal, el corpus se compone de 98 caricaturas en las que el presidente Álvaro Uribe Vélez se encuentra representado visualmente. El primer y segundo período comprenden todas las caricaturas publicadas durante el año, en 2004, 24 y en 2006, 23. Finalmente, el tercer período reúne 52 caricaturas publicadas entre mayo y agosto de 2010. En este último, tomamos solo tres meses en busca de un relativo equilibrio entre los tres períodos, porque solamente estos meses representan el doble de los anteriores.

La diferencia en el total de caricaturas publicadas por Matador en cada uno de los períodos seleccionados se debe a dos factores. En primer lugar, Matador se incorpora como caricaturista a El Tiempo en 2003 y su producción en cantidad fue creciendo paulatinamente. En segundo lugar, a medida que se fueron implementando las diferentes políticas del gobierno de Álvaro Uribe Vélez, este empezó a recibir mayores críticas por parte de la sociedad civil y de sus opositores, principalmente, por la manera de ejercer su función como jefe de Estado (González, 2010; García y Revelo, 2009).

Para analizar nuestro corpus adoptamos una perspectiva semiótica, considerando la información presentada a nivel visual y verbal. En este último caso tuvimos en cuenta los títulos, globos, carteles y etiquetas utilizados por Matador y puestos en relación con los dibujos. Nuestro análisis semiótico se inspira en el enfoque caracterizado por Houdebine (2003) como una "semiología de los índices", en el que los signos se consideran más o menos convencionales en relación con el contexto y con los "valores culturales simbólicos que parecen evocar" (p. 204). 
Esta semiología privilegia así el abordaje del sentido (contenido denotado, referencias temáticas, connotaciones) y su enraizamiento en representaciones colectivas profundas actuales o antiguas (sentido común, estereotipos, imaginarios) (Houdebine, 2003, p. 207. Traducción de las autoras).

Analizamos cada caricatura según cinco dimensiones aplicadas en estudios previos (Pedrazzini, 2011), con algunas variaciones adaptadas al presente corpus en las temáticas analizadas y los personajes representados. Las dimensiones son:

- $\quad$ Períodos de análisis: 2004, 2006 y 2010.

- Temáticas abordadas: se agruparon en tres subdimensiones, política interna, política externa y política mixta. La primera está compuesta por las categorías elecciones, hechos políticos cuestionados, hechos sociales cuestionados, hechos económicos cuestionados y actos de corrupción. Las categorías que contemplan hechos políticos, sociales y económicos cuestionados hacen referencia a decisiones tomadas por el mandatario y que son criticadas por la opinión pública, ya sea por insuficientes, desacertadas o ineficaces. La categoría actos de corrupción, por su parte, refiere a acciones poco transparentes del mandatario o de los funcionarios de su gobierno para obtener algún beneficio particular. Política externa se centra en las acciones diplomáticas. Temáticas mixtas está compuesta por más de un tema nacional o por la combinación de estos con uno internacional.

- Personajes representados: presidente solo, presidente con partidario político, presidente con adversario político, presidente con político o gobernante extranjero, presidente y representante de una entidad pública (Congreso de la República, Senado, Corte Suprema de Justicia, Fiscalía), presidente con personaje civil o profesional, y presidente con representantes de medios de comunicación.

- Relación entre personajes: de colaboración (de amistad, confianza o simplemente conveniencia), de antagonismo, neutra y ausente (en este último caso cuando el presidente es representado solo).

- $\quad$ Rasgos de personalidad: competencia, integridad, carisma y empatía y fiabilidad. Esta última se divide en estabilidad emocional y capacidad de decisión, por un lado, y lealtad y responsabilidad, por otro.

Para codificar la dimensión relación entre personajes, tuvimos en cuenta la proxémica entre los personajes (Alonso Erausquín, 1995), su gestualidad y las emociones expresadas a través de los rostros y cuerpos representados (Eisner, 1998; Gasca y Gubern, 1994); esto último válido también para el análisis de los rasgos de personalidad. A excepción de la dimensión sobre los rasgos, todas las otras son mutuamente excluyentes. Las autoras codificaron las caricaturas separadamente y luego contrastaron sus codificaciones. Los casos de desacuerdo fueron resueltos mediante discusión.

Posteriormente, con el fin de estudiar si los rasgos de personalidad identificados en el personaje de Uribe Vélez varían según los períodos considerados, llevamos a cabo un análisis de correspondencias simples, una técnica de análisis multivariado que proviene 
de la estadística descriptiva. Para ello utilizamos el programa SPAD N 5.6. Este análisis se aplicó a una tabla de contingencia que presentó, en filas, los rasgos de personalidad negativos (como veremos, estos representan el $94 \%$ del total de rasgos identificados), y en columnas, los períodos. El análisis de correspondencias simples proyecta en planos factoriales todas las categorías consideradas y permite formar grupos entre aquellas que tienen una buena representación en el plano factorial y que están próximas en el plano (Benzécri, 1980; Cibois, 2007). Tras este análisis, el regreso al corpus de caricaturas permitió describir y comprender los resultados obtenidos.

Entendemos que este estudio aporta una aproximación novedosa y complementaria al conjunto de trabajos que se han interesado por la figura de Uribe Vélez o por las caricaturas de Matador, al privilegiar un análisis diacrónico, multidimensional y que conjuga técnicas cualitativas y cuantitativas para abordar su objeto. Esto permite identificar regularidades en el conjunto y a la vez profundizar en dimensiones que resultan de especial interés.

\section{Resultados}

\section{Temáticas abordadas}

En la figura 1 observamos que en el año 2004 la temática más abordada por Matador con respecto al Presidente Álvaro Uribe fue la de las elecciones (40 \% de las caricaturas) ya que durante este año se empezó a plantear la posibilidad de una reelección presidencial inmediata y se evidenció el interés del mandatario de continuar en el poder por un período más (ver figura 14). En 2006 esta categoría aparece prácticamente en una de cada cuatro caricaturas debido al proceso de reelección de Álvaro Uribe. En 2010, a pesar de que el mandatario no pudo presentarse como candidato por un nuevo período de gobierno, el tema de las elecciones se mantiene en las caricaturas -aunque en baja, alcanzando 12 \%- puesto que Álvaro Uribe apoyó a su ministro, Juan Manuel Santos, durante la campaña presidencial.

A medida que avanza el gobierno de Álvaro Uribe, Matador incrementa el cuestionamiento a sus acciones políticas, mientras que disminuye sus objeciones sobre la política económica. Con respecto al cuestionamiento a la inversión social, esta categoría tiene su punto más alto en 2004 (13\%), en 2006 está ausente y reaparece con 4 \% en 2010.

En cuanto a las temáticas relacionadas con actos de corrupción, su frecuencia es baja en 2004 y 2006, aumentando de forma considerable en 2010. Estos resultados pueden deberse a que en 2004 su gobierno llevaba solo dos años y, en 2006, la contienda electoral fue un tema privilegiado en la prensa colombiana porque era la primera vez que en una campaña electoral participaba un candidato presidente. Sin embargo, la relevancia que adquiere en 2010 puede obedecer a que desde 2006 hasta el final de su gobierno, e incluso después de terminado, muchos de los funcionarios de Álvaro Uribe fueron acusados de cometer actos irregulares en su desempeño. Algunos de esos actos de corrupción son los que Rincón (2015) denominó hitos y que fueron identificados en las caricaturas de Matador. Un ejemplo es el conflicto de las notarías, en el que se vieron involucrados los hijos del 
mandatario. Otro caso es el de las "chuzadas" del DAS, que refiere a las interceptaciones telefónicas que de manera ilegal llevó a cabo el Departamento Administrativo de Seguridad contra miembros de la Corte Suprema de Justicia, periodistas y opositores del gobierno del presidente Álvaro Uribe.

Con respecto a las acciones diplomáticas, esta categoría no es tratada por Matador en 2004, mientras que en 2006 alcanza el 17 \% de las caricaturas y luego se reduce a un $6 \%$ en 2010 (al menos de forma diferenciada porque como veremos a continuación, es conjugada con otra temática). El tratamiento de asuntos internacionales en 2006 se explica porque a partir de este momento empiezan a ser más profundas las diferencias entre las políticas económicas y de seguridad de Álvaro Uribe con los gobiernos de la región y en 2010 su presencia se debe al rompimiento definitivo de las relaciones diplomáticas entre Colombia y Venezuela. Las temáticas mixtas durante el año 2004 carecen de una presencia fuerte, mientras que en 2006 y 2010 cada una totaliza más del 30 \% de los casos. En 2006 giran alrededor de las relaciones con Estados Unidos y la firma del Tratado de Libre Comercio (TLC) con este país (figura 11), mientras que en 2010 están referidas en su gran mayoría a la crisis de las relaciones diplomáticas con Venezuela y las diferencias que empieza a tener Álvaro Uribe con su sucesor Juan Manuel Santos frente a la solución de la crisis con el país vecino (figura 13).

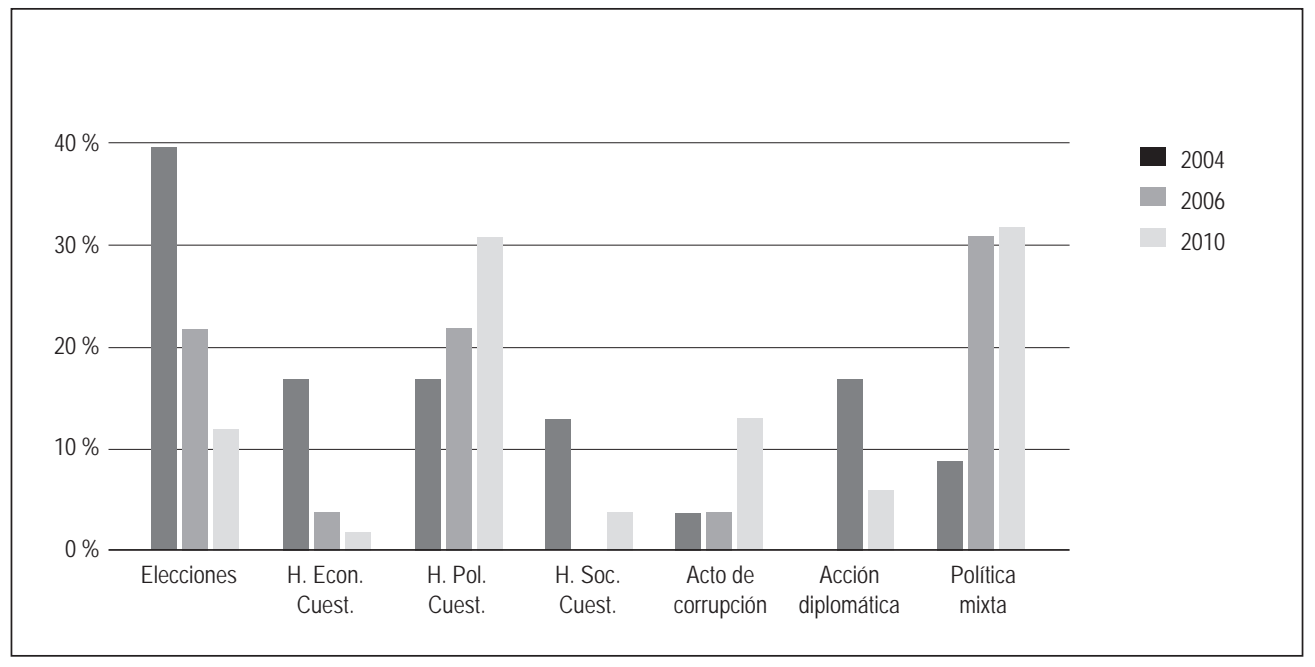

Figura 1. Temáticas abordadas en las caricaturas durante cada uno de los períodos de análisis Fuente: elaboración propia

\section{Personajes representados}

Como puede apreciarse en la figura 2, la representación del presidente Álvaro Uribe solo se mantiene relativamente estable durante los tres períodos, en promedio, una de cada 
cuatro caricaturas (ver figuras 6 y 8). Observando los valores alcanzados por el conjunto de las categorías, su representación en solitud sobresale respecto a otras categorías, como la de estar junto a adversarios políticos, gobernantes extranjeros o periodistas.

Con respecto a la representación de Uribe Vélez con partidarios políticos, esta se incrementa en el transcurso de los períodos, siendo muy elevada en 2010. Durante ese período, en prácticamente la mitad de las caricaturas, el mandatario es representado en compañía de Juan Manuel Santos (ver figura 15), su exministro a quien el Presidente apoya durante la campaña electoral. En cambio, la representación del personaje presidencial con sus adversarios políticos es ínfima: en 2004 y 2006 directamente no existe y en 2010 su frecuencia representa solo un $5 \%$. Estos resultados podrían estar ligados al interés de Matador por enfocarse en las responsabilidades del mandatario por sus acciones y omisiones políticas y a que la delimitación de los adversarios políticos del mandatario fue poco clara (González, 2010; Arrieta 2014).

Una característica recurrente en el estilo de Matador es personificar a las entidades públicas, tales como la Fiscalía General de la Nación y el Congreso de la República. De allí que hayamos otorgado a esta representación el estatus de categoría diferenciada en la dimensión personajes representados. La figura 2 muestra que su presencia se concentra principalmente en 2006 y 2010, años en los que Álvaro Uribe sostuvo una relación tensa con la Corte Suprema de Justicia (ver figura 12) y la Fiscalía debido a diversos hechos de corrupción y sus posteriores investigaciones judiciales.

La categoría Álvaro Uribe con gobernantes extranjeros tiene una distribución diferenciada según los períodos. Es muy baja en 2004 (4 \%) mientras que representa 29 \% de las caricaturas en 2006. Esto se debe a dos factores. Por un lado, a las diferencias que se empiezan a observar entre el mandatario y los gobernantes de la región, especialmente con Evo Morales por las políticas antidrogas y con Hugo Chávez por la firma de un TLC con Estados Unidos. Por otro lado, debido a la cercanía que sostuvo Álvaro Uribe con Estados Unidos en relación con este tratado comercial. El país norteamericano es representado en la gran mayoría de las veces a partir del símbolo del Tío Sam (ver figura 11). En 2010, la categoría disminuye a 11 \% a causa de las distantes relaciones que sostuvo el Presidente con Hugo Chávez y que llevó al rompimiento de las relaciones diplomáticas entre las dos naciones (ver figura 13).

Con respecto a la categoría presidente con civiles/profesionales, observamos que Matador suele acudir a ellos para darle sentido a la situación ficticia que crea en sus caricaturas. Un ejemplo es una imagen publicada el 4 de agosto de 2004, en la que Uribe Vélez es representado como un niño acompañado de su padre, quien recibe de la maestra el boletín del niño. La situación referida es la baja inversión social, los pocos resultados en materia económica, pero la amplia popularidad del mandatario. La representación de civiles y profesionales está presente en un $26 \%$ de las caricaturas en 2004, mientras que en los otros dos períodos disminuye a menos de $10 \%$ (8 \% en 2006 y 3 \% en 2010). 
Por último, la representación de Álvaro Uribe con profesionales de los medios de comunicación (ver figura 14) es bastante marginal y solo alcanza 12 \% sin discriminar los tres períodos, siendo inexistente en el año 2006. Esto último se debe a que, durante este período, el Presidente se negó a participar en debates públicos con los otros candidatos y a dar entrevistas a la prensa (Caracol Radio, 2006).

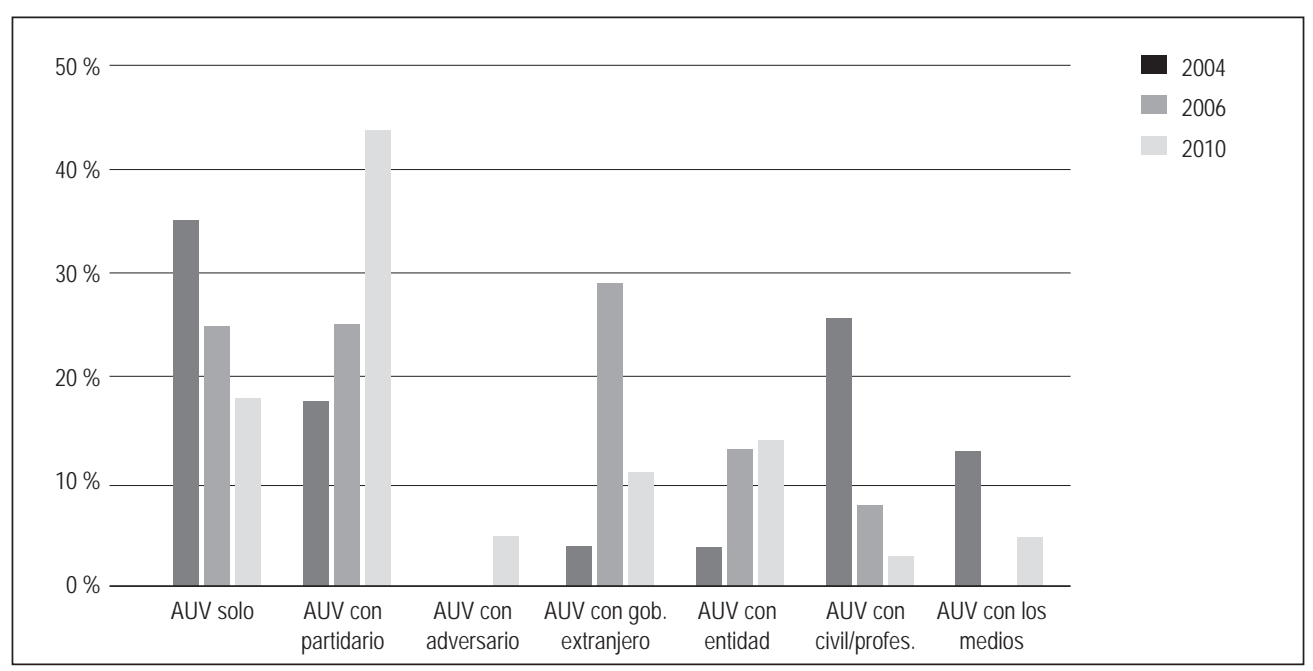

Figura 2. Personajes representados en las caricaturas durante cada uno de los períodos de análisis Fuente: elaboración propia

\section{Relación entre personajes}

De acuerdo con la figura 3, las relaciones de colaboración y de antagonismo entre los personajes representados en las caricaturas tienen una distribución diferenciada: en forma de campana en el caso de las relaciones de colaboración y en aumento a medida que transcurren los períodos en el caso de las relaciones de antagonismo.

En 2004, las relaciones de colaboración entre los personajes representados son superiores a las de antagonismo debido a que Matador representa al mandatario acompañado de sus ministros y de expresidentes que apoyan su reelección presidencial; solo es dibujado sosteniendo relaciones antagónicas con Mafalda, que remite en la caricatura a los congresistas independientes que se opusieron a la aprobación de la ley de reelección (ver figura 9) y a la reacción de algunos sectores sociales frente a sus políticas de gobierno.

También son mayores las relaciones de colaboración en 2006 puesto que durante este período, el jefe de Estado gestiona la firma del TLC con Estados Unidos. Las relaciones antagónicas se van a generar principalmente con los mandatarios de Bolivia y de 
Venezuela debido a sus diferencias comerciales, política antidrogas y a los inconvenientes producidos con los jefes de las autodefensas en el marco del proceso de paz.

No obstante, la frecuencia de las relaciones antagónicas aumenta notablemente en 2010 y alcanza el 42 \% de las caricaturas. Esto podría explicarse porque en 2010, Matador recurre con frecuencia a caricaturizar al Presidente con sus dos principales rivales de ese momento: Hugo Chávez y la Corte Suprema de Justicia, pero también porque hace visible las diferencias que se van generando entre el mandatario y Juan Manuel Santos, después de que este fuera electo presidente de Colombia (ver figura 13).

Las relaciones neutrales entre los personajes alcanzan el $35 \%$ de las caricaturas en 2004, dado que Matador representa al mandatario acompañado de profesionales o periodistas con quienes no mantiene relaciones específicas. En 2006 disminuye a 13 \% en tanto el presidente es representado en su gran mayoría con colaboradores políticos o solo, debido al protagonismo de la campaña presidencial. En 2010 incrementa unos puntos, aunque se mantiene bastante por debajo del pico de 2004.

Como se ha indicado anteriormente, la categoría ausente en las relaciones entre los personajes se debe a que Matador representa a Álvaro Uribe Vélez solo en 23 \% de sus caricaturas. Esto podría obedecer a la centralidad de la figura presidencial en la forma de hacer política del mandatario y, en parte, a una estrategia de Matador, puesto que al ubicarlo como único elemento en su obra hace más visibles sus incongruencias e inoperancias políticas.

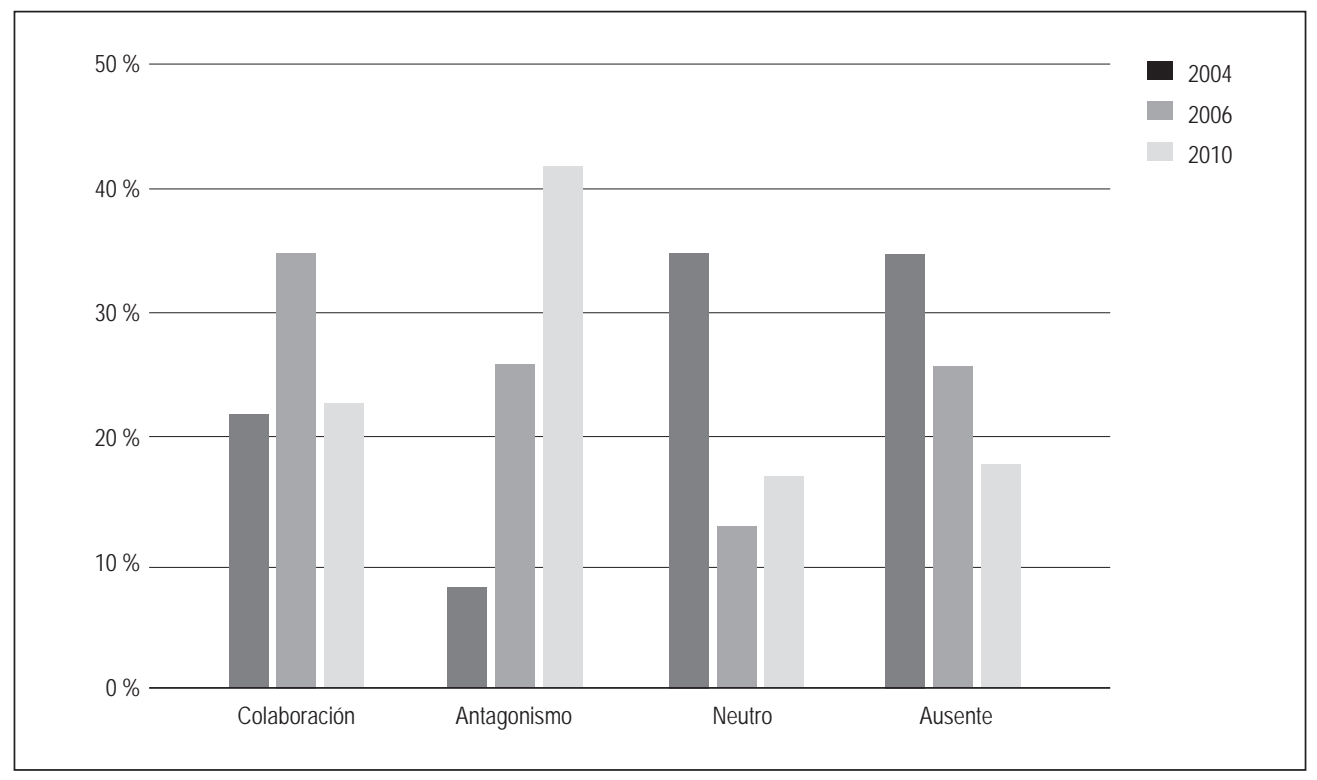

Figura 3. Relación entre los personajes durante cada uno de los períodos de análisis Fuente: elaboración propia 


\section{Rasgos de personalidad}

En la aplicación de la dimensión rasgos de personalidad computamos diferentes categorías para cada caricatura, puesto que en la gran mayoría de las caricaturas encontramos diversidad de rasgos operando de forma simultánea. Hemos identificado 227 rasgos sistematizados durante los tres períodos de análisis: 213 corresponden a rasgos negativos, mientras que 15 corresponden a rasgos positivos.

En la figura 4 observamos que en los rasgos negativos, sobresale la dimensión emocional y capacidad de decisión (19 \%) y lealtad y responsabilidad (15\%). Siguen carisma y empatía e integridad, cada una con un $26 \%$ y finalmente competencia, con un $14 \%$.

De acuerdo con los resultados que observamos en la figura 4, podemos indicar que en este caso la fiabilidad del Presidente es cuestionada y usada para criticar y denunciar sus obsesiones por permanecer en el poder, bien sea por medio de la reelección presidencial inmediata en 2004 y 2006, por presentarse a otro cargo público como la alcaldía de Bogotá, o por el apoyo que brindó al candidato presidencial Juan Manuel Santos en 2010 debido a que veía en este al continuador de sus políticas gubernamentales. La lealtad y responsabilidad del mandatario en su variante negativa se explica por la falta de claridad en negociaciones del TLC con Estados Unidos, principalmente en lo referente al sector agropecuario colombiano.

La dimensión carisma y empatía está relacionada con el autoritarismo, la poca diplomacia usada por el mandatario para conseguir sus propósitos y las actitudes de odio hacia sus adversarios que Matador resalta de Álvaro Uribe en sus caricaturas, como por ejemplo, en el manejo de su conflicto con el presidente Hugo Chávez y con la Corte Suprema de Justicia.

La dimensión integridad está relacionada con actitudes ambiciosas, inescrupulosas y oportunistas en las caricaturas de Matador sobre el presidente Álvaro Uribe, debido a su obstinación por permanecer en el poder. En ellas es representado como un personaje ambicioso y sin límites en el empleo de medios para conseguir lo que se propone. Ejemplos de ello son las caricaturas en las que el Presidente golpea a la Corte Suprema de Justicia a través de la solicitud de un estado de excepción (ver figura 12), implanta su rostro en el de Juan Manuel Santos o impide el restablecimiento de las relaciones diplomáticas entre Colombia y Venezuela destruyendo un puente entre los dos personajes (ver figura 13).

Con respecto a la dimensión competencia, Matador representa a Álvaro Uribe como un gobernante ineficiente debido a los bajos índices de inversión social que caracterizaron a sus dos gobiernos.

Dentro de los rasgos positivos de personalidad, Matador resalta que el presidente Uribe Vélez es un gobernante que logra sus propósitos electorales porque consiguió la aprobación de la ley de reelección, ganó las elecciones en 2006 y su candidato fue electo en 2010. Es fuerte y dinámico porque es capaz de sobrepasar diversos obstáculos para lograr sus propósitos. Es decidido, aunque con un fuerte tono de autoritarismo. 


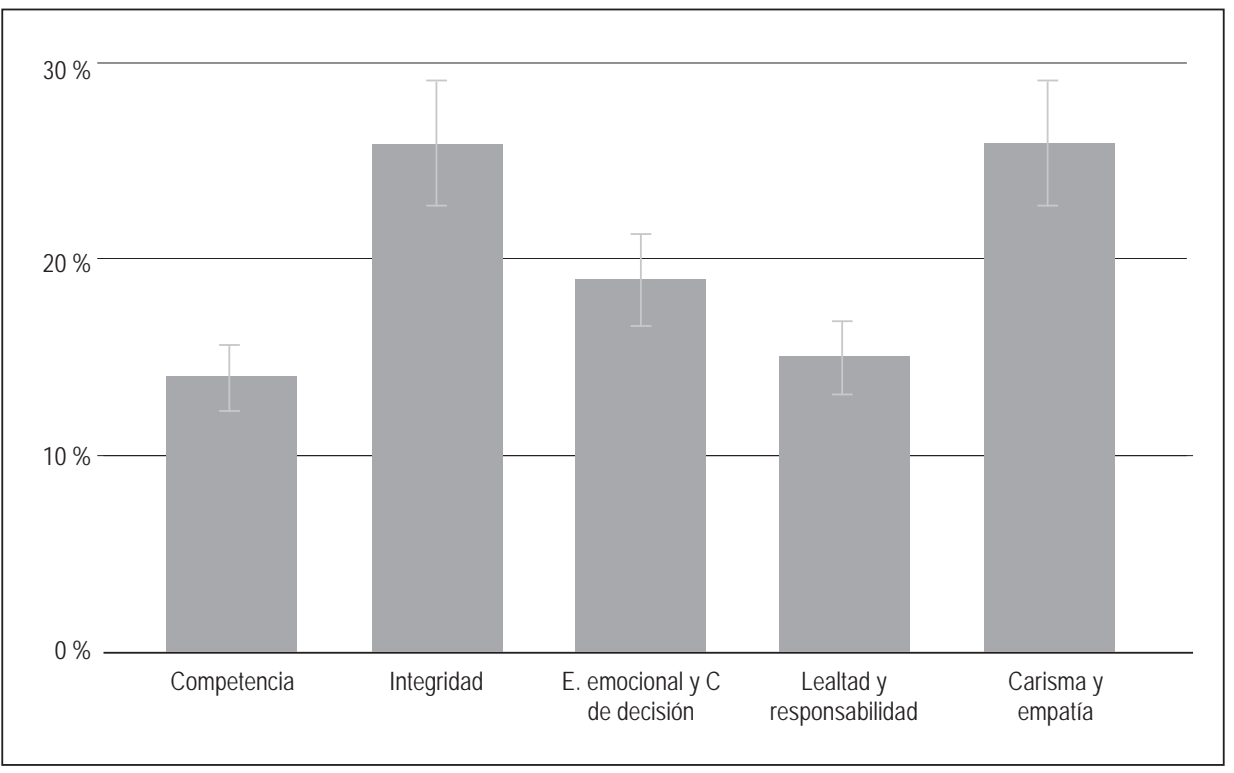

Figura 4. Total de rasgos de personalidad negativos identificados en las caricaturas analizadas

Fuente: elaboración propia

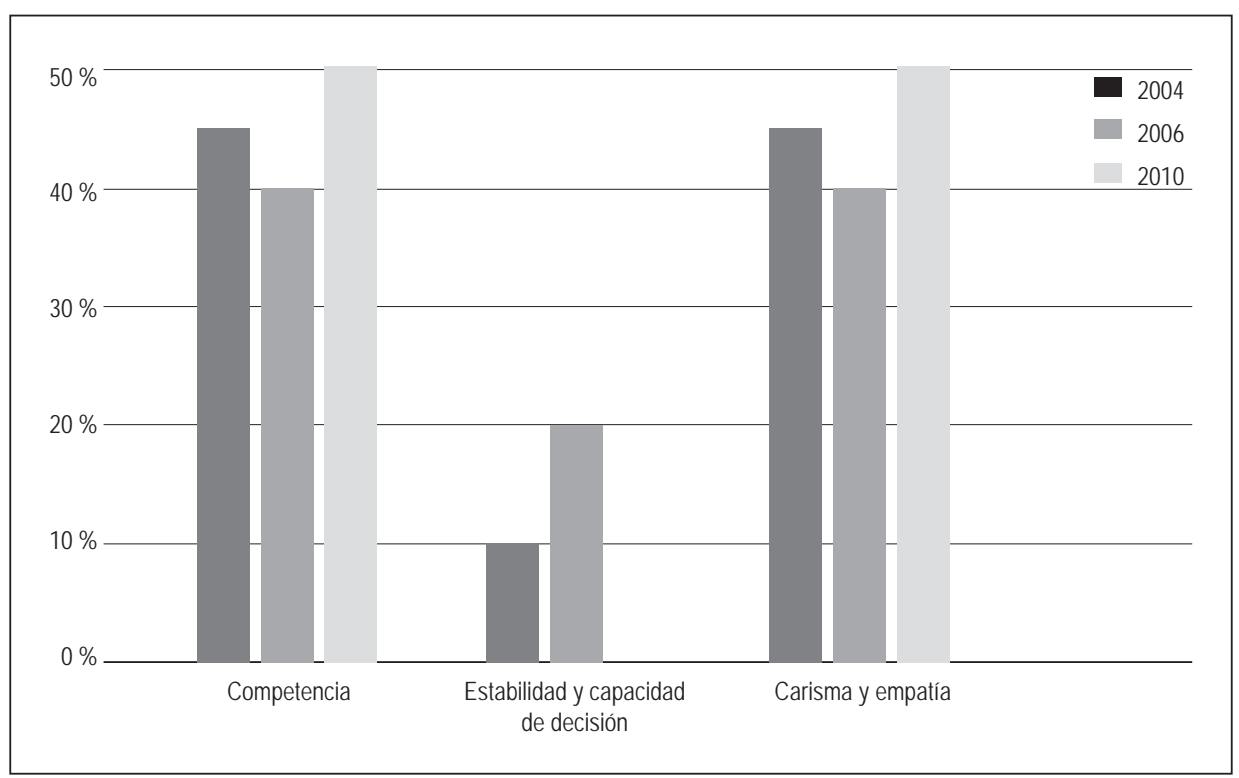

Figura 5. Total de rasgos de personalidad positivos identificados en las caricaturas, discriminados por período de análisis.

Fuente: elaboración propia 
De todos los rasgos positivos identificados, Matador destaca principalmente el logro de Uribe Vélez de ser candidato por un segundo período (32\% de las caricaturas de 2004). Un ejemplo de ello es la figura 6, en la que el Presidente con una banda presidencial que tiene la inscripción 2006-2010, salta holgadamente una valla que representa a la Comisión Primera del Senado. Matador ilustra así el primer triunfo de Álvaro Uribe en la consecución de la aprobación de la ley de reelección presidencial inmediata.

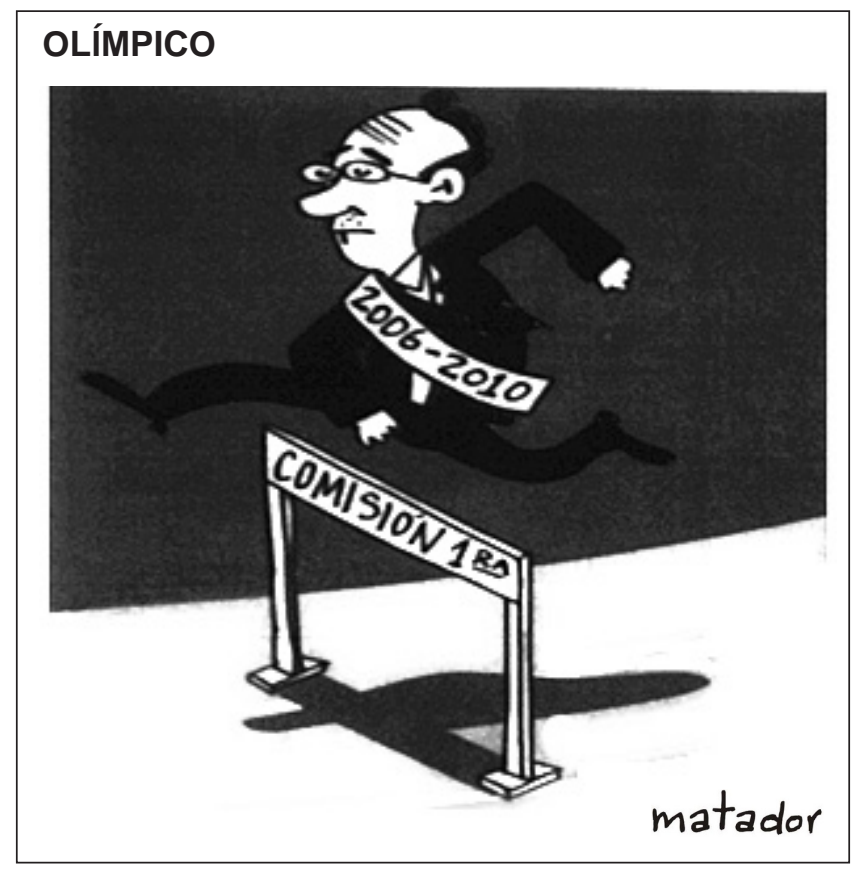

Figura 6. Olímpico

Fuente: Matador, 2004a.

\section{Variaciones de los rasgos de personalidad negativos según el contexto político}

La aplicación del análisis de correspondencias simples permitió identificar ciertas asociaciones entre algunos rasgos de personalidad negativos identificados en el personaje de Uribe Vélez y los períodos analizados. La figura 7 muestra que en el eje 1, las categorías 2004, 2006 y estabilidad emocional y capacidad de decisión se oponen a 2010, carisma y empatía, integridad, lealtad y responsabilidad y competencia mientras que en el eje 2, 2010 y carisma y empatía se oponen a todas las otras categorías.

El análisis de las categorías atendiendo a su proximidad en el plano factorial nos permitió identificar tres grupos, organizados a partir de los períodos considerados.

1. Grupo 2004: asociación del período 2004 con la categoría competencia. 
2. Grupo 2006: asociación del período 2006 con las categorías lealtad y responsabilidad e integridad.

3. Grupo 2010: asociación del período 2010 con la categoría carisma y empatía.

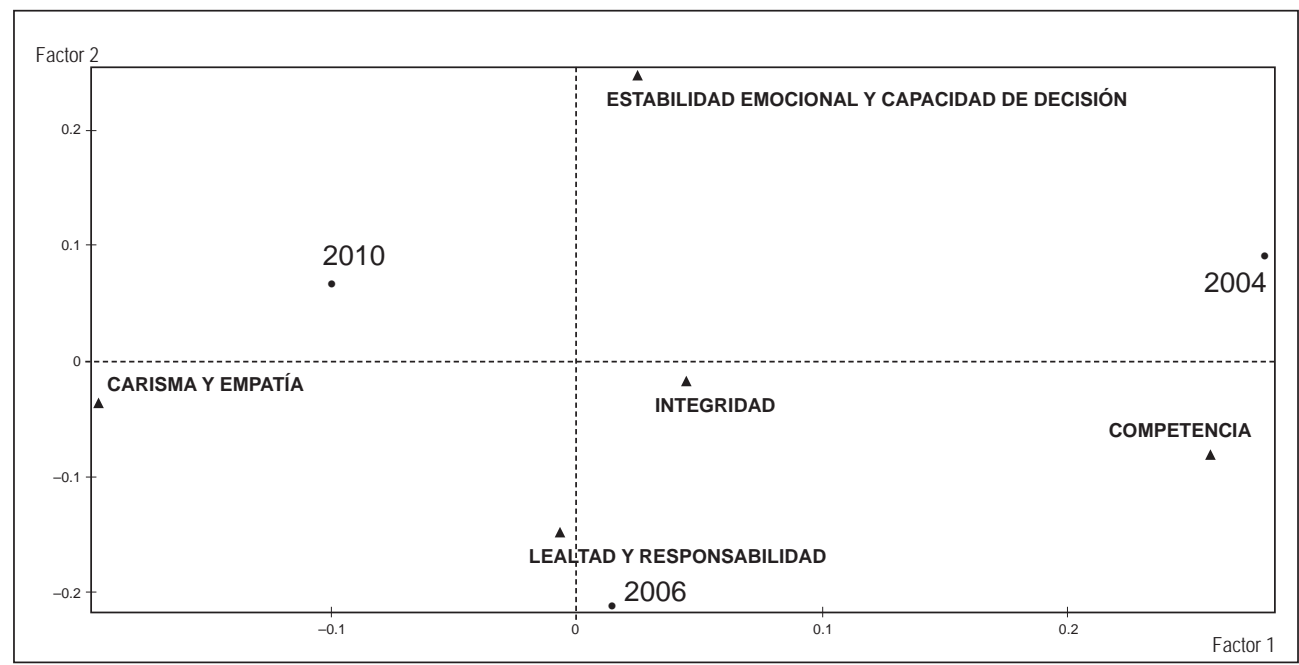

Figura 7. Primer plano factorial del análisis de correspondencias simples aplicado a los rasgos de personalidad negativos identificados en las caricaturas de Uribe Vélez y los tres períodos de análisis

Fuente: elaboración propia

Cabe mencionar que estabilidad emocional y capacidad de decisión se encuentra un poco alejada de las otras categorías, compartida entre los períodos 2010 y 2004. Por su parte, la proximidad de integridad al centro de gravedad indica que se trata de un rasgo bastante compartido entre los tres períodos aunque cobra una representación más significativa en 2006.

A continuación, interpretaremos los resultados a la luz del contexto de publicación de las caricaturas. Para ello, identificaremos los factores más plausibles que permitan explicar la atribución de un rasgo al personaje, ilustrando las interpretaciones con algunos ejemplos. De acuerdo con los resultados observados en la figura 7, el período 2004 se asocia con la categoría competencia en su dimensión negativa. Matador representa al personaje presidencial en situaciones en las que califica como ineficientes sus políticas sociales o económicas. También refiere a su derrota en la consecución del apoyo de los congresistas independientes para la aprobación de la ley de reelección presidencial. Ejemplos de ello son las figuras 8 y 9 . En la primera, el Presidente es representado en la proa de un barco de papel que se hunde. El barco está hecho con un billete de dólar que representa la caída de esta moneda a nivel mundial en ese momento. En la segunda, titulada Reelección hasta en la sopa, Álvaro Uribe recurre a una referencia cultural vastamente conocida, la de Mafalda y su desprecio por la sopa que frecuentemente le prepara su madre. La niña representa a los congresistas independientes e informa al presidente que no apoyarán su ley de reelección. 


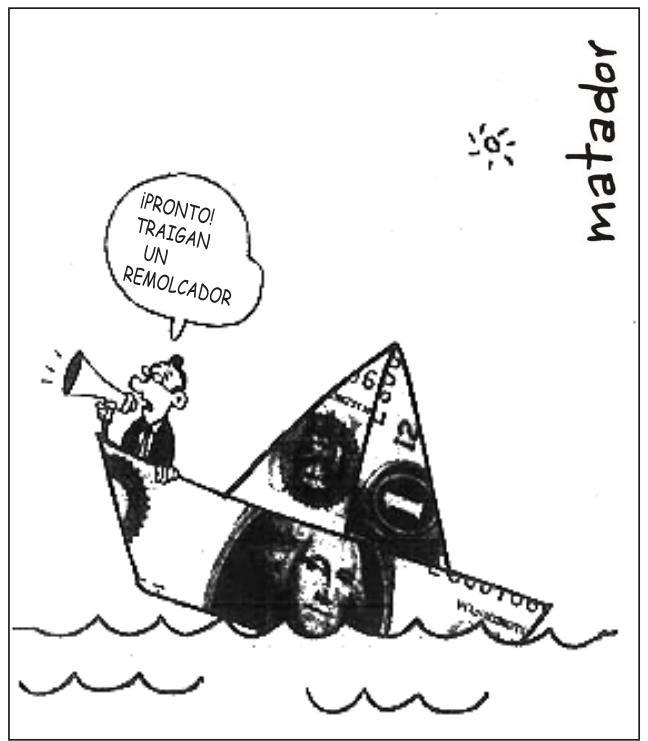

Figura 8. Sin título Fuente: Matador, 2004b.

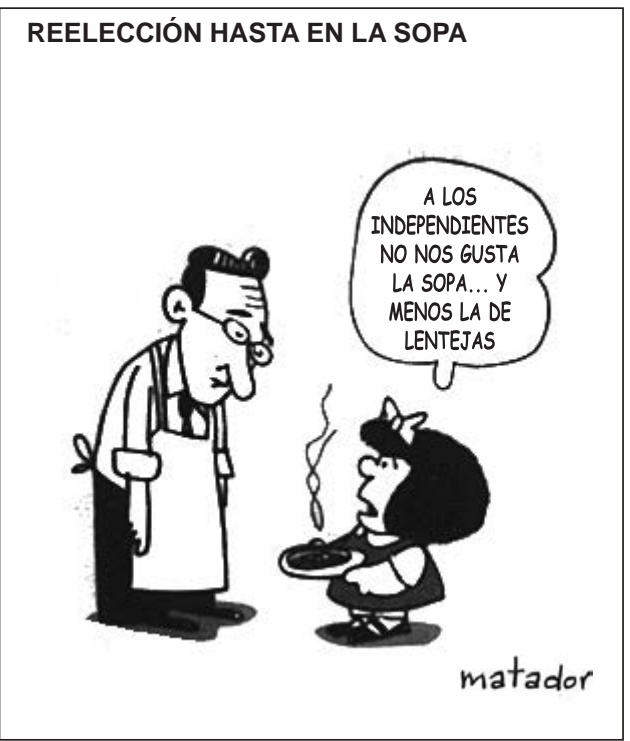

Figura 9. Reelección hasta en la sopa Fuente: Matador, 2004c.

El período de 2006 está asociado a las categorías integridad y lealtad y responsabilidad en su dimensión negativa. En las caricaturas de este período identificamos que el presidente Álvaro Uribe es representado como una persona oportunista y sin escrúpulos debido a sus alianzas políticas durante la campaña electoral. También se lo presenta como irresponsable y desleal con el pueblo colombiano debido a dos factores. Por un lado, a su negativa a participar en debates con el resto de los candidatos de la contienda electoral y por el otro, a la firma del TLC con Estados Unidos en condiciones desfavorables para el país y para la región. Esto último, porque dejaba sin efecto la alianza comercial de la Comunidad Andina de Naciones (CAN). Un ejemplo de su falta de integridad es la figura 10, en la que el Presidente es presentado como un padre bondadoso que se alegra al ver que su hijo pródigo vuelve a las filas del uribismo. Pero estos hijos son los senadores recién electos en marzo de 2006 y que antes de esas elecciones fueron expulsados del uribismo porque se les acusaba de tener alianzas con grupos armados ilegales de extrema derecha. Sin embargo, una vez que estos senadores son electos por una gran cantidad de votantes, Álvaro Uribe vuelve a llamarlos para que apoyen su campaña de reelección. Un ejemplo de su deslealtad e irresponsabilidad es la figura 11, en la que Álvaro Uribe es representado de un tamaño mucho más pequeño que el Tío Sam, connotando una desigualdad importante de poder. El personaje presidencial se encuentra parado sobre una mesa leyendo el texto del TLC, pero este está escrito en una lengua desconocida para el mandatario. Sus problemas de comprensión pueden deberse a una falta de competencia o a que lo que estipula el tratado no resulta muy conveniente para Colombia. 


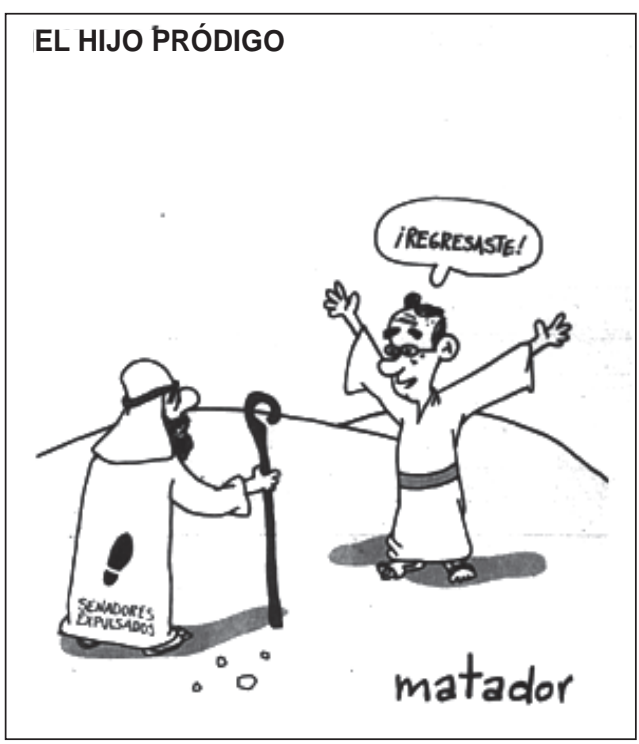

Figura 10. El hijo pródigo

Fuente: Matador, 2006a.

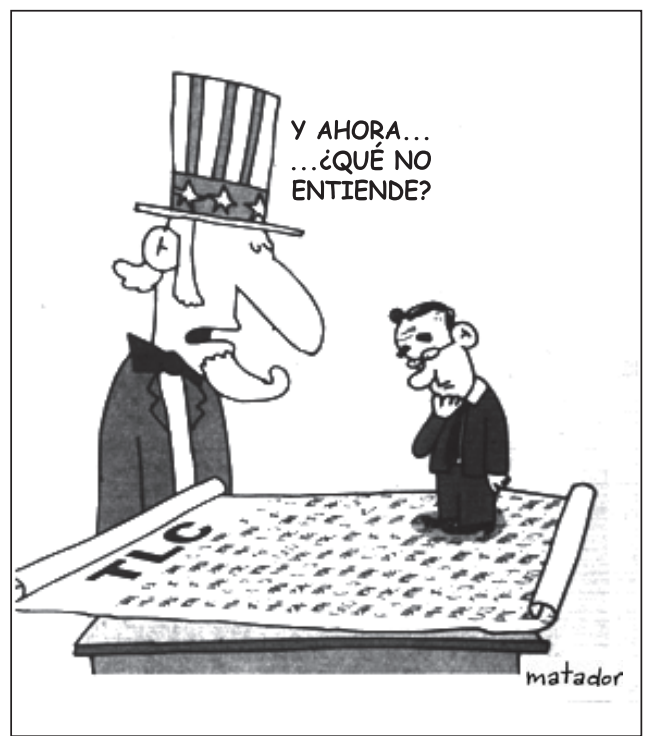

Figura 11. Sin título

Fuente: Matador, 2006b.

Identificamos que el período de 2010 se asocia con la categoría carisma y empatía en su versión negativa. Esto se debe a que el presidente Álvaro Uribe es representado como una persona autoritaria, carente de diplomacia y odiosa. Las caricaturas de Matador critican los métodos poco diplomáticos por parte del Presidente para solucionar sus diferencias con los medios de comunicación, con Juan Manuel Santos, con la Corte Suprema de Justicia y con su par venezolano Hugo Chávez. Con los dos últimos sostuvo diversas diferencias a lo largo de sus dos mandatos. Estableció una lucha de poderes con el sistema judicial colombiano y rompió relaciones diplomáticas con el país vecino. Las figuras 12 y 13 ejemplifican estas situaciones. En la figura 12, titulada Quiere propinar conmoción interior, podemos observar al mandatario tratando de golpear con un mazo a un miembro de la Corte Suprema de Justicia por la espalda. La solicitud de declaración de un estado de excepción que realiza el presidente Uribe Vélez era una manera de obligar a la Corte Suprema a elegir entre los tres candidatos propuestos por él para el cargo de Fiscal General. Por su parte, en la figura 13, titulada Relaciones serruchadas, el Presidente trata de destruir el puente que se ha construido entre Juan Manuel Santos, presidente electo, y Hugo Chávez, para tratar de restablecer las relaciones diplomáticas y comerciales entre las dos naciones. 


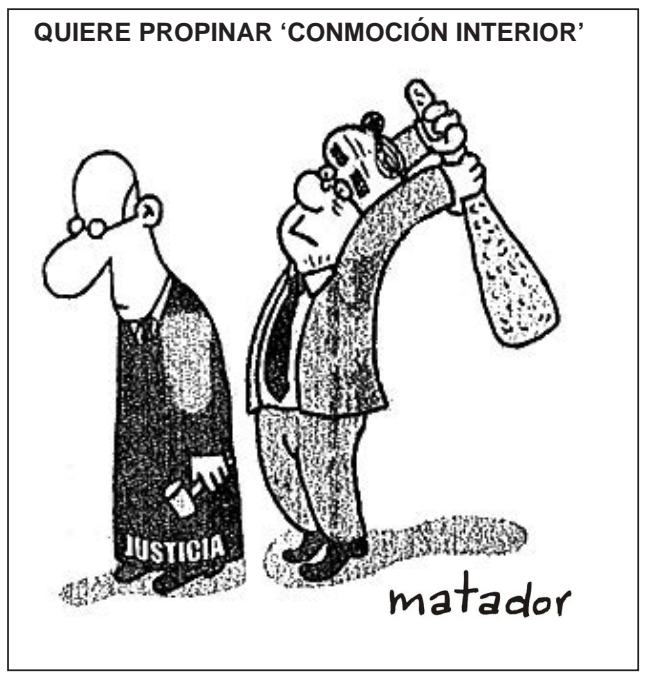

Figura 12. Quiere propinar 'conmoción interior' Fuente: Matador, 2010a.

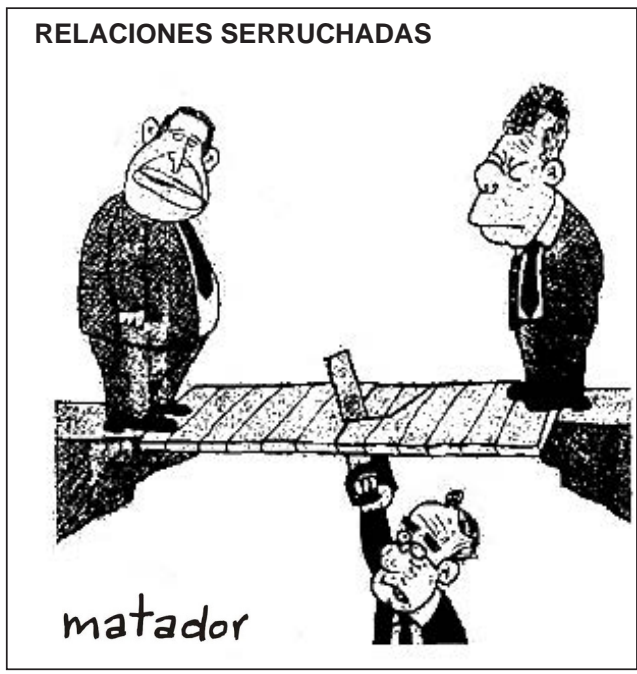

Figura 13. Relaciones serruchadas Fuente: Matador, 2010b.

Tal como hemos mencionado, la categoría estabilidad emocional y capacidad de decisión se asocia con los períodos 2004 y 2010. Este resultado puede responder a que Matador resalta durante estos dos períodos el anhelo y la obstinación del presidente Álvaro Uribe por permanecer en el poder. En 2004 lo hizo a través de la aprobación del proyecto de reelección presidencial inmediata y en 2010 a través de su apoyo a la candidatura presidencial de Juan Manuel Santos y a su interés por ocupar la alcaldía de Bogotá. En las siguientes caricaturas vemos un ejemplo de ello. En la figura 14, observamos que el

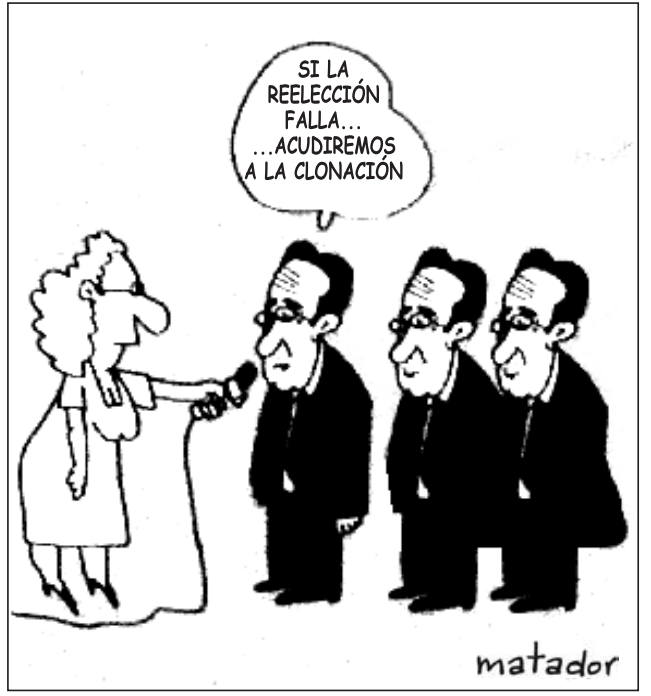

Figura 14. Sin título

Fuente: Matador, 2004d.

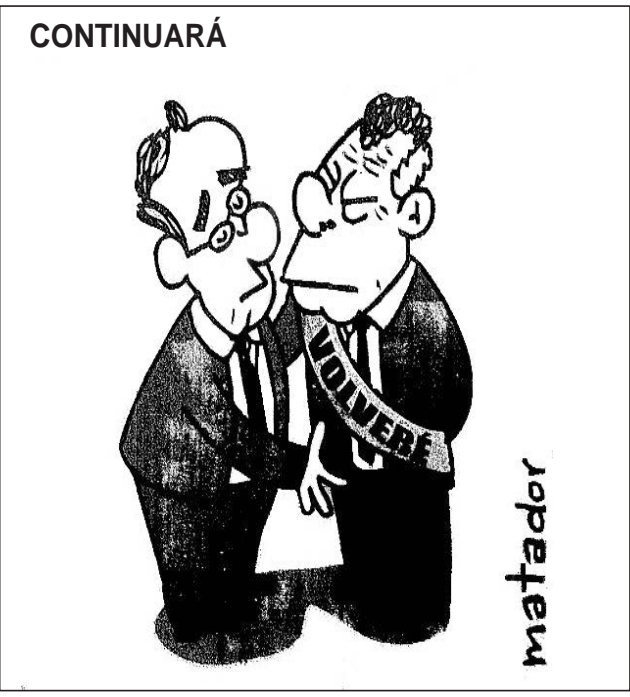

Figura 15. Continuará

Fuente: Matador 2010c. 
mandatario responde a una periodista que recurrirá hasta a la clonación en caso de que el proyecto de reelección no sea aprobado por el Congreso. En la figura 15, titulada Continuará, Álvaro Uribe hace entrega de la banda presidencial a Juan Manuel Santos el día de su ascenso al poder, pero en la banda se lee "volveré".

\section{Discusión y conclusiones}

A partir de un análisis semiótico realizado al corpus de nuestra investigación podemos indicar que Matador focalizó en los aspectos negativos del accionar del Presidente, utilizó sus acciones juzgadas positivas por la opinión pública para transformarlas en cuestionamientos, y puso en tela de juicio los ethe construidos por el mandatario en su discurso.

Nuestros análisis pusieron en evidencia la representación de Álvaro Uribe Vélez como un dirigente ineficiente, irresponsable, carente de lealtad para con el pueblo colombiano, obsesivo por permanecer en el poder, autoritario y poco diplomático en el manejo de los asuntos del Estado. Sin embargo, esos atributos no se mantienen de la misma manera durante sus dos gobiernos, sino que se van pronunciando en algunas coyunturas particulares dependiendo de la agenda política. De esta manera, cada uno de los períodos seleccionados está asociado a una dimensión particular de rasgos negativos de personalidad. El análisis de correspondencias simples permitió identificar la asociación del período 2004 con una caracterización del personaje presidencial de Matador como ineficiente por sus resultados en materia social y económica. En el período 2006, el personaje es identificado como un dirigente desleal y antipatriota por las condiciones desfavorables para Colombia en las que firma el TLC con Estados Unidos y como un mandatario oportunista e inescrupuloso porque se asocia con senadores que no gozaban de una buena reputación política con el objetivo de alcanzar la victoria en las elecciones presidenciales. En el período 2010, en cambio, sobresale la caracterización del Jefe de Estado como una persona autoritaria y poco diplomática debido a su actitud intransigente en la resolución del conflicto con la Corte Suprema de Justicia y con su par venezolano, Hugo Chávez.

Cuando Matador recurre a la representación del mandatario como único personaje de su obra centra en él su responsabilidad frente a los equívocos de su gobierno (Greenberg, 2002), poniendo en cuestión su ethos de responsabilidad evocado por Arrieta (2014). Así, el Presidente es responsable de los malos resultados de la aplicación de las políticas económicas centradas en las inversiones extranjeras y dependientes del precio del dólar como sucedió en 2004. Podríamos decir también que dibujar al personaje presidencial solo en las caricaturas es también una forma de destacar la concentración personalista del poder que diversos autores han señalado en Álvaro Uribe durante sus ocho años de gobierno (García y Revelo, 2009; Camargo, 2010; González, 2010).

El ethos de autoridad asociado a un carácter decidido, fuerte y valeroso (Arrieta, 2014) es puesto en cuestión por Matador cuando focaliza en algunas acciones del mandatario en las que se evidencia su deseo de hacerse obedecer por la fuerza, bien sea de la Corte Suprema de Justicia o de Juan Manuel Santos o en la que es representado sin autoridad 
frente al Tío Sam durante la firma del TLC. El ethos religioso evidenciado para Arrieta (2014) en el mesianismo y paternalismo discursivo del Presidente es satirizado por Matador al polarizar hacia lo negativo su imagen de padre generoso.

En la obra de Matador también podemos observar, principalmente en los períodos 2004 y 2010, la construcción de un ethos satírico obsesivo y ambicioso de poder en el presidente Álvaro Uribe (ver figura 7). Estos resultados coinciden con los de Mondragón y Paz (2013), y también están en sintonía con las declaraciones del propio Matador. Para él, una de las pasiones humanas que identifica en el presidente Álvaro Uribe es su obsesión por el poder (Semana, 2014).

Los resultados obtenidos en este trabajo visibilizan un mecanismo que podríamos caracterizar como recurrente en la caricatura política: su focalización en los hechos y rasgos negativos o la compensación de lo positivo en clave satírica, en donde se transforma lo positivo en negativo o, simplemente, no se menciona lo positivo (Pedrazzini, 2013). Esto último se evidencia en las bajas frecuencias que observamos en 2006 y 2010 de la categoría Álvaro Uribe con personas civiles cuando es sabido que una de las características del gobernante fue la estrecha relación que creó con la población civil a través de los consejos comunitarios y del lenguaje cercano y coloquial que usó para relacionarse con el pueblo colombiano (Camargo, 2010; González, 2010).

Por otra parte, los rasgos de personalidad positivos identificados en las caricaturas de Matador son los de "decidido", "fuerte", "dinámico" y "eficaz". Sin embargo, estos rasgos siempre están asociados a temas de interés particular del Presidente como el fortalecimiento de su partido en el Congreso, la aprobación de la ley de reelección o el triunfo de Juan Manuel Santos en las elecciones presidenciales de 2010.

Podemos concluir que la puesta en relación de las diferentes dimensiones de análisis consideradas -temáticas abordadas, períodos, personajes representados, relaciones identificadas entre ellos y rasgos de personalidad atribuidos al personaje presidencial- nos permiten identificar un ethos posdiscursivo satírico compuesto y dinámico del presidente Álvaro Uribe Vélez. Este ethos se construye sobre la base de diversos rasgos atribuidos al personaje que cobran mayor relevancia en momentos particulares de la coyuntura política colombiana.

Un futuro paso en esta línea de investigación es un análisis en profundidad de los recursos retóricos a partir de los cuales este autor de notable impacto en el contexto político y mediático de Colombia aplica el framing satírico característico de la caricatura política. Esto nos brindará información sobre el funcionamiento y la eficacia de ciertos recursos, así como también sobre su estilo como autor. 


\section{Referencias}

Abraham, L. (2009). Effectiveness of Cartoons as a Uniquely Visual Medium for Orienting Social Issues. Sage Journals, $11(2), 117-165$.

Alonso Erausquín, M. (1995). Fotoperiodismo: formas y códigos. Madrid: Síntesis.

Amossy, R. (2000). El ethos oratorio o la puesta en escena del orador. París: Nathan.

Amossy, R. (2010). La présentation de soi. Ethos et identité verbale. París: PUF.

Arrieta, M. (2014). La construcción del ethos en el discurso político: un caso de legitimación y poder. Cuadernos de Literatura del Caribe e Hispanoamérica, (19), 13-35.

Artunduaga, E. (2014) "Matador": los caricaturistas gozamos de cierta impunidad. Kien y Ke. Recuperado de http://www.kienyke.com/historias/caricaturista-matador/

Barthes, R. (1982). Investigaciones retóricas I. Buenos Aires: Ediciones Buenos Aires.

Benzécri, J. P. (1980). Pratique de l'Analyse des Données. París: Dunod.

Burkart, M. (2017). De satiricón a humor: risa, cultura y política en los años setenta. Buenos Aires: Miño y Dávila.

Camargo, L. (2010). Uribe teve. Cien Días, (70), 31-34. Recuperado de https://issuu.com/cinepppp/ docs/ciendiasno70_082010

Caracol Radio. (2006). Presidente Uribe explicó su ausencia en el debate del Canal Caracol. Recuperado de http://caracol.com.co/radio/2006/05/22/nacional/1148308080_289355.html

Carmona, D. A., (2009). Política y caudillos colombianos en la caricatura editorial, 1920-1950. Medellín: La Carreta Histórica.

Charaudeau, P. (2005). Le discours politique, les masques du pouvoir. París: Vuibert.

Cibois, P. (2007). Les méthodes d'analyse d'enquêtes. París: PUF.

Cromos. (2006). El caricaturista de moda. Recuperado de http://www.colarte.com/colarte/ConsPintores.asp? idartista $=16328 \mathrm{ypest}=$ criticaypagact $=1 \mathrm{ydirpa}=\% 24 \% 241 \mathrm{col} \% 24 \% 24 \mathrm{recuent}$ os\%24\%241 col\%24\%24Caricaturistas\%24\%241 col\%24\%24Matador\%24\%241 col\%24\%24c ritica.html

Constantin, H. (2005). "Je m'engage sur l'avenir": de l'éthos dans les portraits des candidats à l'élection présidentielle de 2002. En J.-C. Seguin (Ed.), Image et pouvoir (pp. 90-99). Lyon: Grimh-LCE-Grimia.

De Sousa, M. y Medhurst, M. (1980). Political cartoons and American Culture: Significant Simbols of Campaing. Studies in Visual Communication, 8(1), 84-97.

Eisner, W. (1998). Comics and Sequential Art. Tamarac: Poorhouse Press.

El Espectador. (2017). Uribe, el expresidente con mayor aceptación. Recuperado de https://www. elespectador.com/noticias/politica/uribe-el-expresidente-con-mayor-aceptacion-articulo-694915 
El País. (2010). Presidente Álvaro Uribe termina su gestión con 80 \% de aprobación. Recuperado de http://www.elpais.com.co/colombia/presidente-alvaro-uribe-termina-su-gestion-con80-deaprobacion.html

El Refaie, E. (2009). Metaphor in Political Cartoons: Exploring Audience Responses. En C. Forceville y E. Urios-Aparisi (Eds.), Multimodal Metaphor (pp. 173-96). Berlín: Walter de Gruyter.

Entman, R. (1993). Framing: Toward clarification of a fractured paradigm. Journal of Communication, 43(4), 51-58.

Gantús, F. (2007). Porfirio Díaz y los símbolos del poder: la caricatura política en la construcción de imaginarios. Cuicuilco, 14(40), 205-225.

García, M. y Revelo, J. E. (2009). La concentración de poder en Colombia. En: M. García y J. Revelo (Eds.), Mayorías sin democracia: desequilibrio de poderes y Estado de derecho en Colombia, 2002-2009 (pp. 328-371). Bogotá: Colección de Justicia.

Garzia, D. (2011). The personalization of politics in Western democracies: Causes and consequences on leader-follower relationships. The Leadership Quarterly, 22(4), 697-709.

Gasca, L. y Gubern, R. (1994). El discurso del cómic. Madrid: Cátedra.

Glass, D. (1985). Evaluating Presidential Candidates: Who Focuses on Their Personal Attributes? Public Opinion Quarterly, 49, 517-534.

González, F. (2010). Gracias, General Uribe, por salvar la patria. Cien Días, (70), 14-18.

Greenberg, J. (2002). Framing and Temporality in Political Cartoons: A Critical Analysis of Visual Nuevas Discourse. Canadian Review of Sociology, 39(2), 181-198.

Houdebine, A. M. (2003). De la viande, aliment ou chair: analyse sémiologique de différents signes de la culture. Revue des Lettres et de Traduction, 9, 203-222.

Kinder, D. (1986). Presidential Character Revisited. En R. Lav y D. Sears (Eds.), Political Cognition, the 19 th Annual Carnegie Symposium on Cognition. Hillsdale: Erlbaum Associates.

Kinder, D., Mark, P., Abelson, R. y Fiske, S. (1980). Presidential Prototypes. Political Behavior, 2(4), $315-$ 337.

Levín, F. (2013). Humor político en tiempos de represión. Clarín, 1973-1983. Buenos Aires: Siglo Veintiuno.

Matador. (07, 06, 2004a). Olímpico. El Tiempo, Bogotá.

Matador. $(21,10,2004 b)$. Sin título. El tiempo, Bogotá.

Matador. (02, 02, 2004c). Reelección hasta en la sopa. El tiempo, Bogotá.

Matador. (17, 02, 2004d). Sin título. El Tiempo, Bogotá.

Matador. (25, 03, 2006a). El hijo pródigo. El Tiempo, Bogotá.

Matador. (17, 05, 2006b). Sin título. El Tiempo, Bogotá.

Matador. (30, 06, 2010a). Quiere propinar 'conmoción interior'. El Tiempo, Bogotá.

Matador. (17, 07, 2010b). Relaciones serruchadas. El Tiempo, Bogotá. 
Matador. (07, 08, 2010c). continuará. El Tiempo, Bogotá.

McAllister, I. (2007). The personalization of politic. En J. Russell, J. Dalton y Hans-Dieter Klingemann (Eds.), Oxford hand6ook of political behavior (pp. 972-1005). Oxford: Oxford University Press.

Miller, J. M. y Krosnick, J. A. (2000). News media impact on the ingredients of presidential evaluations: Politically knowledgeable citizens are guided by a trusted source. American Journal of Political Science,44(2), 295-309.

Miller, A., Wattenberg, M. y Malanchuk, O. (1986). Schematic Assessments of Presidential Candidates. The American Political Science Review, 80(2), 521-540.

Mondragón, F. y Paz, A. (2013). Determinación de los rasgos más característicos de la identidad de presidente evidenciados en la caricatura de 'Matador' en el periódico El Tiempo, durante el último año de gobierno de Álvaro Uribe y el primer año de gobierno de Juan Manuel Santos. (Tesis de pregrado). Universidad Autónoma de Occidente, Santiago de Cali, Colombia.

Montealegre, J. (2014) Carne de estatua: Allende, caricatura y monumento. Santiago de Chile: Mandrágora.

Pedrazzini, A. (2011) La relación verbal-visual en la portada de la prensa cotidiana: el caso atípico de Página/12. Razón y Palabra, 16(77), 1-31.

Pedrazzini, A. (2013). Emphase sur le négatif et couverture informative maigre: deux stratégies rhétoriques pour compenser le positif dans la presse satirique. Thélème. Revista Complutense de Estudios Franceses, 28, 205-219.

Pedrazzini, A. (2017). Construction d'un ethos post-discursif satirique: le Président Jacques Chirac d'après Le Canard enchaîné. Cédille Revista de Estudios Franceses, 13, 379-401.

Rico, G. (2009). Líderes políticos, opinión pública y comportamiento electoral en España. Madrid: CIS.

Rincón, M. (2015). Caricatura y cultura política durante Uribe Vélez, 2002-2010. (Tesis de maestría). Universidad Nacional de Colombia, Bogotá, Colombia.

Semana. (2014). Matador, el agudo caricaturista. Recuperado de https://www.semana.com/gente/articulo/matador-el-agudo caricaturista/400084-3

Semana. (2018). Matador se va de Twitter por amenazas y en las redes se vuelcan para apoyarlo. Recuperado de https://www.semana.com/nacion/articulo/por-que-se-retira-matador-de-lasredesy-el-apoyo-que-ha-recibido/562264

Sánchez Guevara, G. (2011). La caricatura política: sus funcionamientos retóricos. Razón y palabra, 16(78).

Shelton Caswell, L. (2004). Drawing Swords: War in American Editorial Cartoons. American Journalism, 21(2), 13-45.

Solano, C. (2016). El deslenguado Matador habla en vez de dibujar. El Tiempo. Recuperado de http:// www.eltiempo.com/archivo/documento/CMS-16718669

Tillier, B. (1997). La Repubicature. La caricature politique en France 1870-1914. París: CNRS.

Vargas, J. (2013). Entre trazos e ironías: el gobierno de Álvaro Uribe en la caricatura política de Vladdo (Tesis de grado). Universidad del Valle, Santiago de Cali, Colombia. 
Van Hecke, M. (2016). Imag(in)ing the eurocrisis: a comparative analysis of political cartoons. National Identities, 19(1), 129-147.

Wattenberg, M. P. (2004). Personal popularity in U.S. presidential elections. Presidential Studies Quarterly, 34, 143-155.

Wattenberg, M. (2006). Elections: Reliability Trumps Competence: Personal Attributes in the 2004 presidential elections. Presidential Studies Quarterly, 36, 705-713.

Zamora, H. F. (abril 3 de 2018). Matador anuncia que se retira de redes sociales tras recibir amenazas. Recuperado de https://www.semana.com/nacion/articulo/por-que-se-retira-matador-delasredes-y-el-apoyo-que-ha-recibido/562264 